\title{
Review \\ Polymers welding methods including biodegradable materials
}

\author{
Mariusz Fabijański1 ${ }^{*}$, Guofeng Han² \\ 1 Warsaw University of Technology, Poland \\ 2 National Key Labortary for Remanufacturing, Beijing 100072, China, faf428@sina.com \\ * Correspondence: Mariusz Fabijański, mfabijan@wip.pw.edu.pl
}

Received: 02.11.2019; Accepted: 23.01.2020

\begin{abstract}
Welding is one of the most popular methods of joining elements not only from metal materials, but plastics also. Their great diversity, chemical structure and physical condition in which they are at the temperature of use has a significant impact on the quality of the joints made. Welding is a particularly useful method of joining, for example, during the welding of packaging, where biodegradable plastics that dominate in this technology, for example with aluminium foil, dominate. This article reviews the methods of welding plastics including biodegradable materials.
\end{abstract}

Keywords: polymers; polymers welding; welding methods; polylactide PLA

\section{Introduction}

One of the methods of joining polymers is welding. This method has found a very wide range of applications from packaging to very demanding machine parts. Modern welding methods allow joining various polymer materials with different properties and different pour point values [1 $\div 3]$. This also applies to biodegradable plastics, which are increasingly used for packaging and the need to seal them tightly [4]. An example of such a material is polylactide. Polylactide (PLA) belongs to the family of biodegradable plastics and is often called "double green" due to the fact that it is obtained from renewable raw materials and is completely degraded under appropriate environmental conditions. This is undoubtedly its biggest advantage. However, it is not very competitive in price compared to traditional plastics, which is why fillers are added to reduce the price. These additives often affect the welding process of this material. In addition to unnamed and unlike material-plastic joints, the market is increasingly expecting plastics to be welded to materials other than plastics, for example aluminum foil, laminated paper, and here there are problems associated with the appropriate selection of welding method and technology to ensure the required strength of such a connection, continuity and tightness, which is of great importance in the case of food packaging

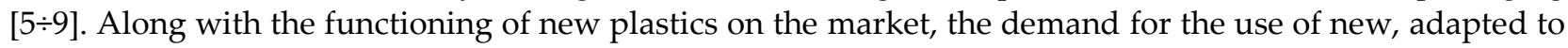
these materials, methods of welding, enabling the welding of elements of a complicated shape, increases.

This work reviews the welding methods that can now be used to connect polymer materials, including biodegradable materials, using polylactide as an example.

\section{Polymers welding - basics of the process}

Welding is the process of joining thermoplastic components without the use of intermediate materials by applying heat to the joined places and plastic state, and then pressing the molten surfaces. As a result

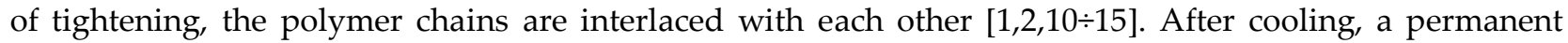
connection is created. The welded joint is diffusive and the strength properties depend on the size and duration of the pressure.

Depending on the method of heat input, the following welding methods are distinguished:

- by heating the inside of the surfaces to be joined

In this method, welding is carried out using a heating element that provides heat to the objects to be joined. The heating element can be a wedge, plate or rod. The heat needed to heat two elements can be created by rubbing welded objects. A characteristic feature of these methods is the introduction of heat to the joined plastic objects from the side of their joining, while maintaining the non-plasticized external condition of the product [15].

- by heating the outside of the surfaces to be joined 
In this method, heat is applied through the entire thickness of the joined elements from the outside using a heating rail, wire, strip, etc. In this method of joining, two basic methods are distinguished: contact and impulse welding. Use thin-walled elements, such as foils [15].

- by generating heat inside the connected elements

This method depends mainly on the thermal and electrical properties of the joined materials. The heat needed to make the weld is brought directly to the joint, the tool is cold and pressure is applied. These include ultrasound and high frequency welding technologies $[15,16]$.

The selection of the welding method depends mainly on the thermal and electrical properties of the material and the shape of the surface of the joined elements [1].

\section{Polymers welding methods}

\section{Hot wedge welding}

This method involves gradual plasticizing of the edges of joined objects with a hot metal wedge sliding along the edges of the joined elements while maintaining their contact. Pressure exerted on the elements to be joined can be carried out by means of a roller or rail. This method is used to connect foils and thin plates. The joints created as a result of this operation have the nature of overlaps [13:17]. Figure 1 shows a scheme of mechanical hot wedge welding.

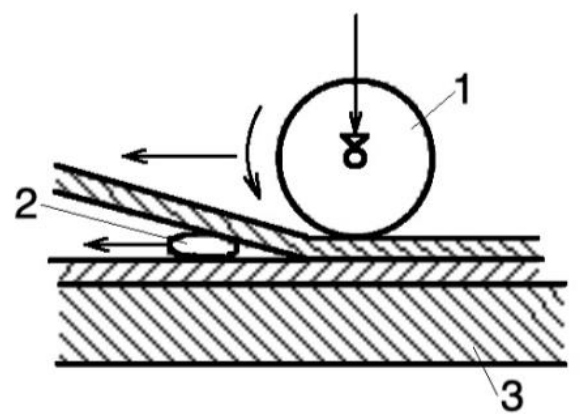

Fig. 1. Scheme of foil welding with a hot wedge, 1 - pressure roller, 2 - heating wedge (pressure), 3 - washer

For manual welding with a hot wedge, electric soldering tools with a power of $100 \div 250 \mathrm{~W}$ are used, after prior replacement of the soldering tip with a copper (nickel-plated) welding wedge. Wedge temperature during welding, e.g. PVC should be $250 \div 300{ }^{\circ} \mathrm{C}$, HDPE: $220 \div 260{ }^{\circ} \mathrm{C}$, LDPE: $190 \div 220{ }^{\circ} \mathrm{C}$, PMMA: $260 \div 300{ }^{\circ} \mathrm{C}$, PLA: $205 \div 220{ }^{\circ} \mathrm{C}$. The presented welding method is used to make long, straight-line joints $[2,7,8]$. It can be carried out manually and mechanically. The manual welding technique combines elements over $0.5 \mathrm{~mm}$ thick, and the machine technique - over $0.2 \mathrm{~mm}[12 \div 17]$.

\section{Hot plate welding}

"Hot plate" welding consists of plasticizing the surface of the elements to be welded by means of a hot plate introduced during welding between the surfaces to be joined. Then the heating plate is removed and the bonded surfaces of the elements are pressed together. In this way, butt joints are obtained, for example: pipes, profiles, sections and rods made of hard PVC, polyolefins, PMMA and other materials. For welding elements up to $250 \mathrm{~mm}$ in diameter, the plate is usually circular, while for larger diameter values, welded elements are ring-shaped. In order to prevent the plastic material from sticking, the surface of the heating plate is covered with a parting agent, e.g. a cloth impregnated with PTFE $[1,17,18]$. Figure 2 shows the hot plate welding scheme.

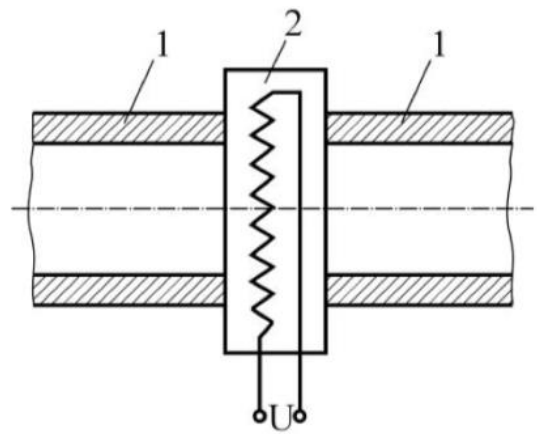

Fig. 2. Scheme of welding by means of a heated plate [2]: 1 - joined elements (pipes), 2 - heated plate (flat) 
Welders of this type are equipped with thermoregulators that allow maintaining the temperature at a certain level, devices for inserting and removing the heating plate and jaws fixing the welded elements and

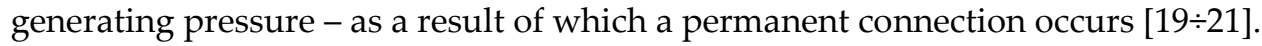

A very important aspect in this connection method is to generate the appropriate pressure and coaxial arrangement of the elements. This has a significant impact on the quality of the joint [22].

\section{Friction heat welding}

The source of heat in the friction welding process necessary to plasticize the polymer material is the friction work on the surfaces of the joined elements. Depending on the manner of mutual friction of these elements, a distinction is made between rotary welding - usually called friction welding and vibration welding $[2,19 \div 22]$.

The friction welding method is used to connect pipes, rods or other cylindrical elements made of thermoplastic polymers with a diameter of up to $500 \mathrm{~mm}$. The process is usually carried out in a semiautomatic device, working on the principle of a spindle. This method is used for example to make globular polyamide floats for fishing nets and fuel filters for passenger cars [20]. An example of friction rotary welding is shown in Figure 3.

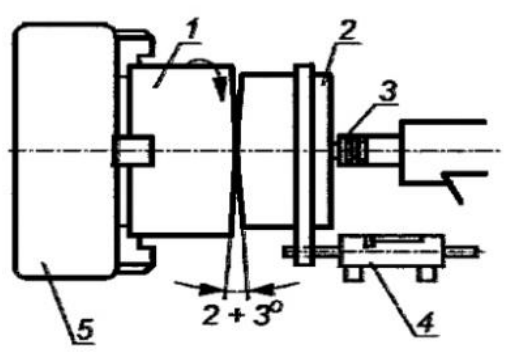

(a)

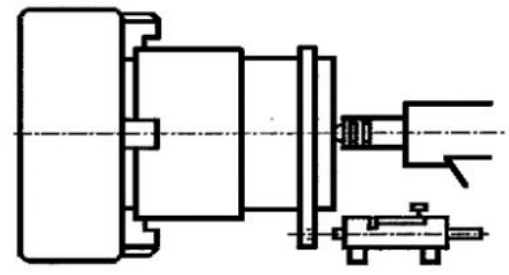

(b)

Fig. 3. Friction rotary welding of polymers [2]: a) before the welding process, b) welded elements; 1 -rotating welded element, 2 - immobile welded element, 3 -rotating center, 4 - switch, 5 - spindle centering handle

In order to obtain an even temperature of the welded elements, their faces should be shaped in an appropriate way. The temperature is more uniform, the larger the contact surface of the parts to be welded. The friction welding method is especially recommended for joining elements made of materials susceptible to oxidation at elevated temperature, e.g. polyamides. This is due to the fact that the heating of the bonded surfaces takes place almost without the access of air. Due to the low thermal conductivity of the materials, weld thickness and deformation of the joint cross-section are relatively small [20].

The relative strength of the joints made by friction welding is $80 \div 90 \%$ for hard PVC, $90 \div 95 \%$ for polyethylene $60 \div 70 \%$ for polyamides and up to $85 \%$ for polymethyl methacrylate $[1,2]$.

\section{Contact welding (resistance)}

Contact welding, also known as resistance welding or hot electrode welding, is one of the oldest and also the most common methods of joining foils. This method involves pressing the elements with one heated strip to a cold surface or pressing the joined elements between two heated strips. Double-sided heating makes it possible to weld foils of greater thickness, above $0.1 \mathrm{~mm}$, due to a more favorable temperature distribution in the cross-section of the combined layers. According to the presented principle, manual (portable) clamp welding machines and automatic devices designed for the production and closing of foil packaging are constructed. To eliminate the sticking of the plasticized foil to the metal heating elements, the electrode surface is coated with silicones, PTFE or glass fabric, saturated with these materials [1,2,12]. Figure 4 shows a diagram of foil contact welding and temperature distribution in the materials to be joined.

Sometimes, heating elements are used in the shape of knives, tapes or wires, which after pressing the joined layers of foil cause their cutting, with simultaneous binding of the cut edges. The temperature of the heating element depends on the type of foil being bonded and is $300 \div 400{ }^{\circ} \mathrm{C}$. At the intersection of the foil, a characteristic thickening forms, ensuring good joint strength. This method of welding, referred to as welding with a tape or a glow wire, is mainly used in the automatic production of bags, as well as for connecting polypropylene, polyamide and polyester foils $[2,12 \div 15]$. 


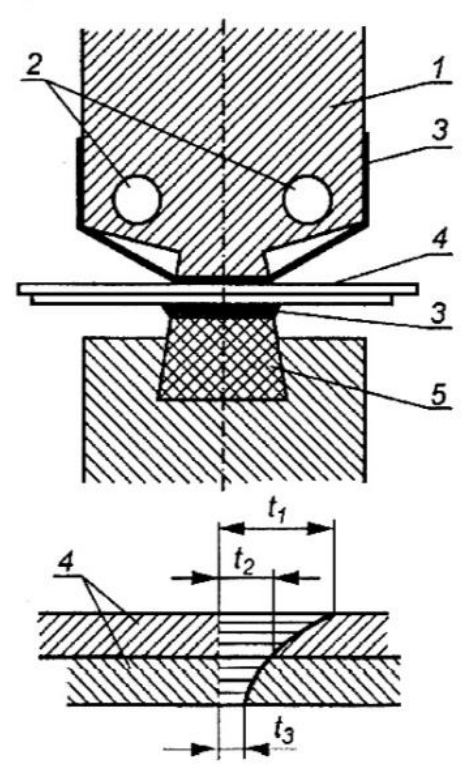

(a)

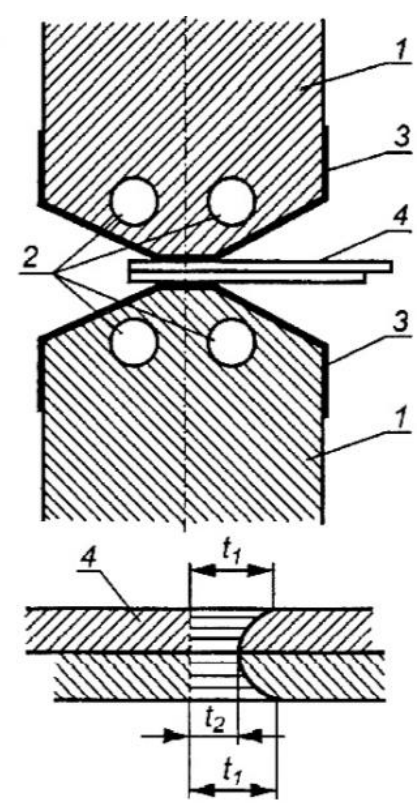

(b)

Fig. 4. Scheme of polymers foil welding and temperature distribution in welded materials [2], a) heating by means single electrode, $b$ ) heating by two electrodes, 1 - electrode, 2 - heating elements, 3 - PTFE pad, 4 - foil, 5 - rubber pad; $t_{1}$-electrode temperature, $t_{2}$ - temperature of welding, $t_{3}$ - lowest temperature of welded foil.

\section{Impulse welding}

The impulse welding process consists of squeezing the edges of joined foils between quickly heated and then quickly cooled strips. As in contact welding, the heat flows to the heating element through the foil to the welding place, except that the element is heated not continuously, but by a short pulse of high-power electric current. The pulse duration is regulated depending on the type and thickness of the sealed foils, and amounts to $0.171 \mathrm{~s}$. In the case of thinner foils welding, the pulse is applied unilaterally (to one electrode), and when welding thicker foils - bilaterally. The squeezing strips are equipped with impulse tape, which, having a small heat capacity, heats up quickly after passing current through it and cools quickly after it is turned off. In order to prevent the material from sticking to the metal, PTFE spacer are used, which are placed between the resistance tape and the welded foils [1,23]. Figure 5 shows an impulse welding scheme.

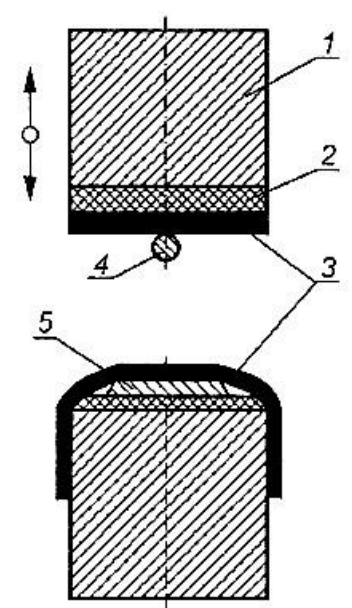

Fig. 5. Scheme of impulse welding with cutting off [2]: 1 - pressure bar, 2 - porous rubber spacer, 3 - PTFE spacer, 4 - wire, 5 - impulse tape

The advantage of the impulse welding method is the cooling of the joint under pressure (with compact compression bars), which limits the possibility of its damage before complete cooling, e.g. when filling a freshly formed package. The scope of its use is limited by the thickness of the materials being joined. For one-sided heating, foils up to $0.2 \mathrm{~mm}$ thick can be welded, and for two-sided - up to $0.5 \mathrm{~mm}$. The impulse welding process is mainly used for the production of packaging with simultaneous filling. The production of packaging is 
usually associated with simultaneous foil cutting. Welding with cutting off can be carried out, among others when using a flat impulse tape with heated wire on the opposite side of it $[2,10,22]$.

\section{High frequency welding}

High frequency welding, or RF welding (due to the radio frequency used) is a process of bonding nonconductive thermoplastic materials as a result of their heating by supplying energy of an alternating electric field, most often with a frequency of approx. $27.12 \mathrm{MHz}$, with the interaction of pressure exerted through the press for the combined elements $[1,23,24]$.

This process involves the application of high frequency voltage, increasing the amplitude of vibration of particles of the material being welded (dielectric). This translates directly into increasing the heat and thus the temperature of the material until it reaches a plastic (semi-liquid) state. Another factor determining the connection is the pressure of the heated areas of two (or more) layers of material in such a way that they are joined. This is usually carried out in a press system with a properly set pressure. One pair of metal electrodes (press plates) are responsible for heating and pressure, the shape of which corresponds to the weld. Through them, the pressure of the elements is exerted and high frequency voltage is supplied. The welding process takes a very short time, after which we obtain a homogeneous weld with high strength, tightness and aesthetic appearance [24].

The most commonly used materials used in high frequency welding are the following thermoplastics: PVC, PU, PET-A, PET-R, PET-G, EVA [1,2].

HFW welding enables very precise control of the energy dosage delivered to the material. The resulting weld is stabilized, because under the continuing pressure of the press, the joined elements cool down. In many cases, this is the only way of joining and welding, which ensures obtaining welds with the desired quality parameters [24].

The advantage of this method is the combination of materials with different thermoplastic properties and different thermal conductivity, for example, hard foil with cardboard [24].

\section{Ultrasonic welding}

The mechanism of ultrasonic welding consists of the fact that the heat necessary to plasticize the joined edges is generated as a result of changes in the field of compression and tensile strength as well as the microfriction of the joined surfaces, caused by mechanical ultrasonic vibrations with a frequency of about $20 \mathrm{kHz}$. As a result, ultrasonic vibrations reach the joint area causing friction on the surface of the joined elements, and thus heat is generated, which causes plasticization of the joined materials. The time of ultrasonic welding usually does not exceed $1 \div 2 \mathrm{~s}$ and depends on the type of material as well as the thickness and shape of the joined elements $[1,25 \div 27]$.

A high-frequency current is applied to the transducer from the generator, and the transducer changes electrical vibrations to mechanical vibrations of the same frequency. A vibrating mandrel (sonotrode) is connected to the transducer, which transmits mechanical vibrations to the welded materials. The mandrel (anvil) placed opposite to the sonotrode serves to absorb vibrations and dissipate the heat generated [25].

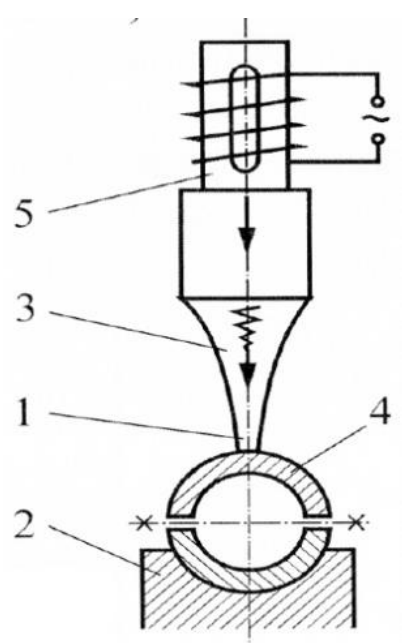

Fig. 6. Scheme ultrasonic direct welding [2], 1 - sonotrode, 2 - anvil, 3 - waveguide, 4 - welded elements, 5 - ultrasonic transformer 
Materials with high mechanical vibration transfer capacity, i.e. materials with a high modulus of elasticity (PC, PMMA, thermoplastic polyesters, styrene and acetal plastics, and poly-phenylene oxide) are suitable for joining with this method. Plastics with a partially crystalline structure are characterized by higher energy losses in comparison to amorphous plastics and therefore require higher generator output power or welding times [26,27].

To obtain a connection with adequate mechanical strength, the surfaces of the elements to be joined must be properly shaped, e.g. by making a triangular projection in one of them. In such a performance, the heat release process intensifies, which causes rapid plasticization of the material [27].

Depending on the materials being welded, there are direct ultrasonic welding, which is used for plastics with a low elasticity coefficient, and indirect ultrasonic welding, used for plastics with a high elasticity coefficient [2]. Figure 6 shows a direct ultrasound welding scheme.

Ultrasonic welding, due to the high cost of the device, is used in cases of mass production. Examples include: car parts, electronics parts, consumer goods as well as in packaging production [25,27].

\section{Vibration welding}

Vibration welding is one of the methods of joining plastics in which heat for the joining process is obtained as a result of friction caused by relatively low frequency vibrations. The parameters of this process are the vibration amplitude, frequency, time and pressure, as in the case of friction, ultrasonic and high frequency welding. Vibration welding is characterized by a frequency of 100 to $300 \mathrm{~Hz}$ and a vibration amplitude of 0.2 to $3.5 \mathrm{~mm}$. It follows that individual welding methods are based on the same idea, significantly differ from each other in the frequency of the process [1,29]. In the vibration method, one of the combined elements performs movement and simultaneously pressure is realized. This process takes place until the contacting elements generate heat in the friction process, enabling them to go into plastic state and to mix the molten phase and create a joint.

The movement performed by one part of the connected elements can be linear or oscillating. Mechanical, electromagnetic and hydraulic devices and systems are used to generate vibrations. Each of these methods offers different frequency ranges and vibration amplitude. The choice of method depends on the type of material, the shape of the combined elements.

The vibration welding process consists of four phases [1,2,30]:

- phase "1", so-called dry friction, during which the rubbing surfaces of the joined elements are heated, and the transition to a liquid state occurs,

- phase "2", so-called an undetermined period of fluid friction, during which a thin layer (foil) of plasticized material is produced,

- phase "3", so-called quasi-stationary fluid friction, during which the molten materials mix, pressure occurs and the process of vibration generation ends,

- phase "4", so-called cooling, which consists of a stage of dynamic pressure, and then of maintaining this pressure until the connection site cools down.

The undoubted advantage of this method is the possibility of joining together various materials, amorphous with partially crystalline and, for example, thermoplastic materials with hardening plastics. Such a connection has the character of a mechanical meshing, where an additional material is introduced and the strength of the connection depends on it $[28 \div 30]$.

Due to the fact that vibration welding involves the generation of heat due to friction, the joint should be designed in such a way as to allow freedom of relative linear or oscillatory movement of the joined elements. Another important parameter during designing is taking into account the shape of the surfaces to be joined so that it is possible to apply pressure of the required size and facilitate the weld formation process, which has a direct impact on the quality and strength of the connection [29].

\section{Laser welding}

Laser welding is one of the joining methods in which a concentrated beam of laser radiation is used as the source of heat necessary for plasticizing the surface of elements. In this process, the laser beam provides heat, heating the material by absorbing the radiation. The absorption properties of individual materials are different, and therefore the appropriate radiation wavelength is selected for the specific material.

In the process of making the connector, some of the radiation is reflected and transmitted. This type of behavior is affected by the structure of the polymer itself, the proportion of additives such as dyes and fillers. For example, partially crystalline polymers, due to crystallites, scatter radiation and thus increase absorption [2, 35]. 
By precisely controlling the plasticizing process, this method can be used for materials that could not be combined in any other way. The advantage of this technology is a very aesthetic and practically narrow connection zone. It is also possible to combine elements of complex shapes without exerting additional pressure [31,32]. Figure 7 shows a diagram of butt laser welding. The generated laser radiation passes through the "laser-transparent" upper layer and is absorbed by the "absorbing" lower layer. Absorbed radiation (some of it) is converted into heat. It is conducted from the surface to the upper and lower levels, causing the material to melt and form a weld. Thermoplastics generally transmit light in the infrared energy range, therefore the laser bonding process requires the use of additives to increase the absorption capacity of the polymer. In many cases of laser welding, the energy absorber is carbon black. Its advantage is the absorption of energy of any wavelength, while the disadvantage is black coloring of the connection. Another way to increase absorption is to add an organic absorber to the material [33 $\div 35]$.

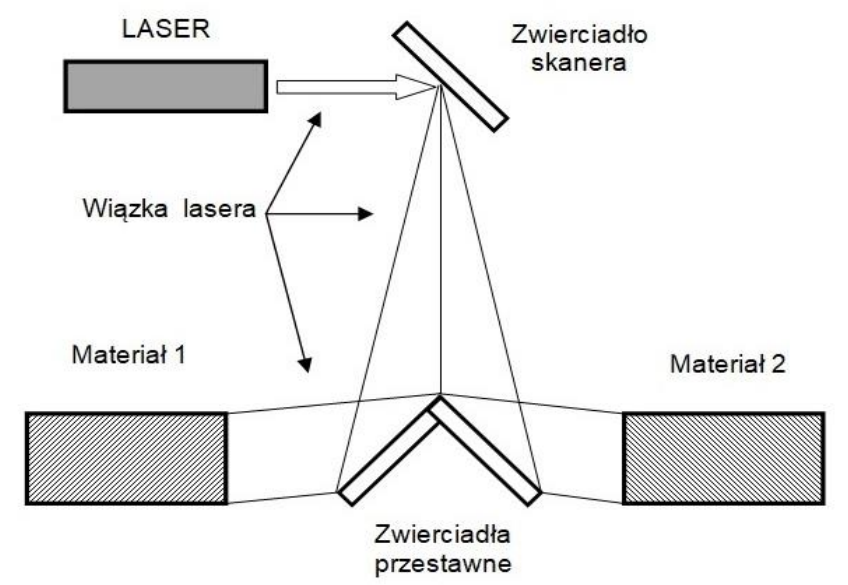

Fig. 7. The Scheme of laser butt welding of polymers [2]

\section{Summary}

From the beginning, man has used various tools and has been developing them all the time. At some point, the problem arose of joining various elements and hence the development of gluing and welding technology. Welding as one of these methods has found application especially for joining polymers as the fastest and most effective.

The variety of these materials, construction and different values of plasticization (processing) and degradation temperatures cause significant difficulties in joining two different materials. Welding, in this case, is the most advantageous technology due to the fact that it allows joining various materials, including biodegradable polymers, while maintaining adequate weld strength as well as geometry and aesthetics of the connection. This technology uses different ways to bring heat to the connection point and to exert pressure and vary its duration. Thanks to this, we can combine almost all materials, while maintaining approximately $90 \%$ of the original strength of the native material [18].

In the case of biodegradable plastics, polylactide (PLA) is the most widely used, from packaging to medicine. In the case of packaging, it is necessary to combine (by means of welding) it with other materials, not necessarily polymeric. High accuracy and tightness of connections must be maintained here. On the one hand, it is required that the packaging protects the product that will not be damaged as long as possible, while on the other hand, the packaging, if possible, is degraded as soon as possible without significant environmental load. Polylactide has found widespread use in medicine, such materials are subject to high and stringent requirements depending on the material properties and the specific application. Polymers used for implants must have tissue compatibility (biocompatibility), both themselves and their breakdown products must not be toxic to the body. This material is often used for bolts and bone joint plates [36]. Since there is a need to connect two or more elements, welding is the most appropriate technique when it is necessary to connect such elements, because no additional materials are introduced, and the connection is very precise and accurate.

At present, there is an increased demand for plastic joining technology and dynamic development of modern microprocessor-controlled and fully automated devices allowing very precise control of the process and thus also the quality of the connection [1]. The selection of appropriate welding technology is therefore a very important element in the design of machine parts and their connections. This affects the subsequent use of the finished product. 
Author Contributions: conceptualization, M.F. and G.H.; analysis, M.F. and G.H.; resources, M.F.; writingoriginal draft preparation, M.F.; writing-review and editing, M.F. and G.H.; visualization, M.F.; supervision, M.F.

Funding: This research received no external funding.

Conflicts of Interest: The authors declare no conflict of interest.

\section{References}

[1] Jasiulek P., Joining of polymers by welding and adhesive bonding. "KaBe" Publishing House, Poland 2006.

[2] Wilczyński K. (editor.), Garbarski J., Nastaj A., Lewandowski A., Fabijański M., Wilczyński K.J., Buziak K, Narowski P., Zawistowski H., Processing of polymer materials, Publishing House of Warsaw University of Technology, 2018.

[3] Skowrońska B., Chmielewski T., Pachla W., Kulczyk M., Skiba J., Pres W., Friction Weldability of UFG 316L Stainless Steel. Archives of Metallurgy and Materials, 2019, Vol. 64(3), 1051-1058. http://dx.doi.org/10.24425/amm.2019.129494

[4] Przewodowski D., Golański D., The effect of technological parameters of PMMA thermoplastic welding in the hot air stream on the quality of the joints. Welding Technology Review, Vol. 91(8), 13-24. https://doi.org/10.26628/wtr.v91i8.995

[5] Fabijański M., Mechanical properties of polylactide wood composites. Przem. Chem., 2019, Vol. 98(8), $1246-1248$. http://dx.doi.org/10.15199/62.2019.8.6

[6] Fabijański M., Mechanical strenght and flammability of polyactide. Przem. Chem., 2019, Vol. 98(4), 556-558. http://dx.doi.org/10.15199/62.2019.4.8

[7] Fabijański M., Garbarski J., The effect of multiple processing on the strength of polylactide/polypropylene mixture. Przem. Chem., 2017, Vol. 96(3), 567-570. http://dx.doi.org/10.15199/62.2017.3.16

[8] Fabijański M., Effect of calcium carbonate addition on mechanical properties of polylactide. Przem. Chem., 2017, Vol. 96(4), 894-896. http://dx.doi.org/10.15199/62.2017.4.33

[9] Fabijański M., Study on mechanical properties of phosphogypsum-filled polylactide. Przem. Chem.,2016, Vol. 95(11), 2227-2229. http://dx.doi.org/10.15199/62.2016.11.15

[10] Fabijański M.,Multiple processing of polylactide. Przem. Chem., 2016, Vol. 95(4), 874-876. http://dx.doi.org/10.15199/62.2016.4.33

[11] Kowieski S., Mikno Z., Pietras A., Resistance welding of modern high-strength steels. Biuletyn Instytutu Spawalnictwa w Gliwicach, 2012, Vol. 56(3), 46-51.

[12] Mikno Z., Kowieski S., Bartnik Z., Derlukiewicz W., Projection welding in the finite element calculation. Welding Technology Review, 2013, Vol. 85(11), 64-70. https://doi.org/10.26628/ps.v85i11.184

[13] Zubrzak B., et al., The use of electromagnetic energy in industrial devices for welding plastics. Przeglad Elektrotechniczny, 2017, Vol. 93(1), 245-248.

[14] Nakonieczny L., Wieczorek G., Technology of ultrasonic welding of plastics. Spajanie Metali i Tworzyw w Praktyce, 2004, 24-26.

[15] Dziuba S., Welding methods for thermoplastics used in the construction of gas pipelines and defects in buttwelded joints. Instal, 2001, Vol. 12, 6-8.

[16] Jasiulek P., Welding thermoplastic film using the hot wedge method. Spajanie Metali $i$ Tworzyw w Praktyce, 2003, 1-2, 14-17.

[17] Rydzkowski T., Michalska-Pożoga I., Development of Techniques of materials joining - welding of plastics. Welding Technology Review, 2015, Vol. 87(11), 18-21. https://doi.org/10.26628/ps.v87i11.523

[18] Wałęsa K., Malujda I., Talaśka K., Zgrzewanie termoplastycznych pasów cięgnowych metodą gorącej płyty, Przegląd Mechaniczny, 2018, 6, 23-27. https://doi.org/10.15199/148.2018.6.2

[19] Węglowska A., Pietras A., Impact of preheating on the quality of vibration welded joints made of polyamide PA66 glass fiber reinforced. Przetwórstwo Tworzyw, 2013, 154, 410-413.

[20] Salacinski T., Chmielewski T., Winiarski M., Cacko R., Świercz R, Roughness of Metal Surface After Finishing Using Ceramic Brush Tools. Advances in Materials Science, Vol. 18(1), 2018, 20-27. https://doi.org/10.1515/adms2017-0024

[21] Chmielewski T., Golański D., The role of welding in the remanufacturing process. Welding International, 2015, Vol. 29(11), 861-864. https://doi.org/10.1080/09507116.2014.937604

[22] Kudła K., Wojsyk K., Selected Possibilities of the FSW and FSSW Methods in the Removal of Material Defects and Welding Imperfections. Biuletyn Instytutu Spawalnictwa w Gliwicach, 2017, Vol. 61(5), 117-122. 
[23] Mingareev I., Weirauch F., Olowinsky A., Shah L., Kadwani P., Richardson M., Welding of polymers using a 2 $\mu \mathrm{m}$ thulium fiber laser. Optics \& Laser Technology, 2012, Vol. 44(7), 2095-2099.

https://doi.org/10.1016/j.optlastec.2012.03.020

[24] Scott P. F., Smith W., Key parameters of high frequency welding. Tube International, 1996, 15,147-152.

[25] Baake E., Nikanorov A., Ebel W., Numerical Modeling of Double High-Frequency Longitudinal Welding of Cladded Pipes. In:2019 XXI International Conference Complex Systems: Control and Modeling Problems (CSCMP). IEEE, 2019. p. 199-202.

[26] Chen Y. J., Yue T. M., Guo Z. N., Fatigue behavior of titanium/PET joints formed by ultrasound-aided laser welding. Journal of Manufacturing Processes, 2018, Vol. 31, 356-363. https://doi.org/10.1016/j.jmapro.2017.11.027

[27] Vendan S. Arungalai, et al., Ultrasonic Welding of Polymers. In: Confluence of Multidisciplinary Sciences for Polymer Joining. Springer, Singapore, 2019, 73-101.

[28] Volkov S. S., Nerovnyi V. M., Kobernik N. V., Ultrasonic Cutting of Polymers. Russian Engineering Research, 2018, Vol. 38(6), 446-449. https://doi.org/10.3103/S1068798X18060187

[29] Rahmi M., Abbasi M., Friction stir vibration welding process: modified version of friction stir welding process. The International Journal of Advanced Manufacturing Technology, 2017, Vol. 90(1-4), 141-151. https://doi.org/10.1007/s00170-016-9383-9

[30] Pal K., et al., An investigation on vibration welding of amorphous and semicrystalline polymers. Materials and Manufacturing Processes, 2016, Vol. 31(3), 372-378. https://doi.org/10.1080/10426914.2015.1019111

[31] Raza S.F., Khan S.A. Mughal M.P., Optimizing the weld factors affecting ultrasonic welding of thermoplastics. The International Journal of Advanced Manufacturing Technology, 2019, Vol. 103(5-8), 2053-2067. https://doi.org/10.1007/s00170-019-03681-7

[32] Golański D., Chmielewski T., Skowrońska B., Rochalski D., Advanced Applications of Microplasma Welding. Biuletyn Instytutu Spawalnictwa w Gliwicach, 2018, Vol. 62(5), 53-63. https://doi.org/10.17729/ebis.2018.5/5

[33] Becker F., Potente H., A step towards understanding the heating phase of laser transmission welding in polymers. Polymer Engineering E Science, 2002, Vol. 42(2), 365-374. https://doi.org/10.1002/pen.10954

[34] Bachmann F. G., Russek U. A., Laser welding of polymers using high-power diode lasers. In: Photon processing in Microelectronics and Photonics. International Society for Optics and Photonics, 2002, 505-518. https://doi.org/10.1117/12.470660

[35] Ilie M., et al., Through-transmission laser welding of polymers-temperature field modeling and infrared investigation. Infrared Physics \& Technology, 2007, Vol. 51(1), 73-79. https://doi.org/10.1016/j.infrared.2007.02.003

[36] Ruśkowski P., Gadomska-Gajadhur A., Polilaktyd w zastosowaniach medycznych. Tworzyw sztuczne w przemyśle, 2, 2017, 32-35.

(C) 2020 by the authors. Submitted for possible open access publication under the terms and conditions of the Creative Commons Attribution (CC BY) license (http://creativecommons.org/licenses/by/4.0/). 